\title{
TAENIA MULTICEPS (CESTODA): Ia ANTIGEN EXPRESSION AND PROSTAGLANDIN SECRETION BY PARASITE-MODIFIED, MURINE PERITONEAL MACROPHAGES
}

\author{
RAKHA N.K.*, DIXON J.B.* \& CARTER S.D.*
}

\section{Summary :}

Taenia multiceps secretions modify accessory cell activity in macrophages. The present experiments were designed to elucidate the cellular mechanisms involved. While normal, murine peritoneal macrophages amplified mitogen-activated T-cell proliferation, macrophages modified by exposure to parasite secretions inhibited this proliferation. The modified behaviour was shown by glutaraldehyde-fixed as well as living macrophages, and modification was inducible by FPLC fraction 24 of coenurus fluid and was associated with an expanded population of la $^{-}$macrophages. Secretory products of parasite-activated macrophages also inhibited T-cell proliferation, and secretion was prevented by indomethacin. The measurement of modified accessory activity was not influenced by the concentration of tritiated thymidine in lymphocyte proliferation assays. Consequently there is no evidence that the reported events are affected by macrophage-derived, cold thymidine secretion. It is concluded that T. multiceps is able to manipulate macrophage accessory function by mechanisms which involve altered histocompatibility antigen expression and the secretion of prostaglandin.

KEY WORDS : Taenia, coenurus, accessory cell, macrophage, T cell, cytokine, histocompatibility, prostaglandin, immunoregulation, Echinococcus, hydatid.

\section{INTRODUCTION}

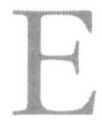
xposure to soluble factors from Taenia multiceps impairs the accessory function of macrophages in presenting mitogenic signals to lymphocytes (Rakha et al., 1991a). The parasite components which mediate this modification can be separated chromatographically from other immunologically active components of T. multiceps, such as the T-cell mitogenic factor. The macrophage modifying fraction of T. multiceps has been shown to impair the rosette forming response of murine lymph-node cells to sheep erythrocytes (Rakha et al., 1991b), but the same fraction is also an antigen which induces antibody response in the natural ovine infection (Rakha et al., 1992). Since modification of accessory function

\footnotetext{
* Department of Veterinary Pathology, University of Liverpool, PO Box 147, Liverpool L69 3BX, U.K.

Correspondence: J.B. Dixon. Tel.: 0151-794-4207. Fax: 0151-794-4219.

E-mail daysman@liv.ac.uk.
}

Résumé : TAENIA MULTICEPS (CESTODA): L'EXPRESSION DES ANTIGÈNES IA ET LA SÉCRÉTION DES PROSTAGLANDINES PAR LES MACROPHAGES DU PÉRITOINE MURIN MODIFIÉS PAR LE PARASITE

Les sécrétions de T. multiceps modifient la fonction accessoire des macrophages. Ces expériences ont été mises au point pour en élucider les mécanismes. Les macrophages normaux du péritoine murin augmentent la mitose des lymphocytes $T$, stimulée par les mitogènes; cependant les macrophages modifiés par les sécrétions parasitaires inhibent cette mitose. La fonction modifiée est observée dans les macrophages fixés par la glutaraldehyde, comme dans les macrophages vivants, et la modification pourrait. être induite par la fraction FPLC 24 du fluide du coenurus et est associée à une population élargie des macrophages sans antigène la. Les sécrétions des macrophages stimulés par le parasite inhibent aussi la mitose des cellules $T$, et la sécrétion est empêchée par l'indométhacine. La valeur de la fonction modifiée n'est pas influencée par la concentration de $3 \mathrm{H}$-thymidine dans les tests de mitose lymphocytaire. Par conséquent les évènements décrits ne résultent pas de la sécrétion de la thymidine non radioactive par les macrophages. On en conclut que T. multiceps peut manipuler la fonction accessoire des macrophages par des mécanismes qui impliquent une modification de la production des antigènes d'histocompatibilité, et la sécrétion de prostaglandine.

MOTS CLÉS : Taenia, coenurus, cellule accessoire, macrophage, cellule T cytokine, histocompatibilité, prostaglandine, réglementation de l'immunité, Echinococcus, kyste hydatique.

is a potential means for the parasite to regulate the host's primary and secondary response to antigen, it appears important to identify changes in macrophage membrane structure or secretory behaviour which are characteristic of the modified state. The present report describes increased frequency of $\mathrm{Ia}^{-}$cells in modified murine macrophage populations, and the secretion, by an indomethacin-sensitive mechanism, of a soluble suppressor of lymphoproliferative response to T-cell mitogens

\section{MATERIALS AND METHODS}

\section{EXPERIMENTAL DESIGN}

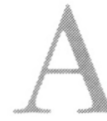
ccessory cell activity is defined for present purposes as the ability of a cell to enhance the proliferative response of $\mathrm{T}$ cells to plant mitogens. Accessory activity is measured by adding macro- 
phages in progressively increasing concentration to lymph-node cells proliferating under the influence of concanavalin A (ConA) or phytohaemagglutinin. Proliferation is estimated by tritiated thymidine uptake. Normal macrophages are competent accessory cells and therefore enhance lymphoproliferation in proportion to their concentration. Measurement of accessory activity in the macrophages is in terms of the gradient of the plot of thymidine uptake against macrophage concentration (Kadian et al., 1996).

\section{ANIMALS}

$\mathrm{BALB} / \mathrm{c}$ mice (2-3 months of age) were maintained under standard laboratory conditions and used for inoculation of parasite material and as the source of macrophages and lymph-node cells.

\section{T. MULTICEPS PRODUCTS}

T. multiceps coenurus fluid (TMCF) was obtained during treatment of field cases of ovine coenuriasis as described by Skerritt and Stallbaumer (1984). T. multiceps protoscolex culture supernatant (TMSN) was prepared by culturing protoscoleces in tissue culture medium based on RPMI-1640 as described by Rakha et al., (1991a).

To make chromatographic fractions of T. multiceps products, TMCF was fractionated on a FPLC-mono Q (DEAE) column as described by Rakha et al. (1991b). Fractions were collected, dialysed against PBS at $4{ }^{\circ} \mathrm{C}$ overnight, filtered sterile and stored at $-20^{\circ} \mathrm{C}$.

\section{INOCULATION SCHEDULE}

To produce populations of parasite-modified peritoneal macrophages, BALB/c mice were injected intraperitoneally either once with $0.8 \mathrm{ml} \mathrm{TMCF}$, twice at 7 days interval with $0.8 \mathrm{ml}$ of FPLC fraction 24 of TMCF (TMCF F24), or twice at 7 days interval with $0.8 \mathrm{ml}$ of TMSN. Control macrophages were taken from uninoculated mice or from mice injected with tissue culture medium.

\section{PREPARATION OF LYMPHOCYTES}

Mesenteric lymph nodes were removed aseptically from mice and homogenised by sieving in phosphatebuffered saline, pH 7.2 (PBS) containing $2.5 \%$ neonatal calf serum (NCS). Washed cells in $10 \mathrm{ml}$ of $\mathrm{PBS} / \mathrm{NCS}$ were layered onto Histopaque (Sigma), centrifuged at $400 \mathrm{~g}$ for $30 \mathrm{~min}$ and the interface cell population washed three times with PBS/NCS. Macrophagedepleted lymphocytes were prepared by incubating the washed lymph-node cells in plastic Petri dishes for $2 \mathrm{~h}$ at $37{ }^{\circ} \mathrm{C}$ in $5 \% \mathrm{CO}_{2}$. The cells not adherent to the Petri dish were then collected and used in accessory cell assays. Macrophage depletion by this method has been found to reduce the variability of the lymphocytes' response to ConA, but not to abrogate the response.

\section{MACROPHAGES}

Macrophages were recovered by washing the peritoneum with heparinised RPMI-1640 medium immediately post mortem, and purified by adhesion to plastic for $4 \mathrm{~h}$ at $37^{\circ} \mathrm{C}$ as described by Cox et al. (1986).

\section{Cell Viability}

Viability was assessed by suspending cells at a dilution of $1: 10$ in $0.1 \%$ trypan blue and counting in a haemocytometer.

\section{ACCESSORY CELL ASSAY}

Macrophage-depleted lymph-node cells were cultured in $200 \mathrm{ml}$ wells of sterile, round-bottom 96-well microtitre plates. Each well contained $2.4 \times 10^{5}$ cells to which ConA was added to give $5.0 \mathrm{mg} / \mathrm{ml}$ final concentration. Other culture conditions were as described by Dixon et al. (1982). Macrophages were added to triplicate lymph-node-cell cultures in numbers between 5,000 and 60,000 cells per culture. After $48 \mathrm{~h}$ incubation at $37^{\circ} \mathrm{C}$ in $5 \% \mathrm{CO}_{2}$, cultures were pulsed with $1.0 \mathrm{mCi} /$ well tritiated thymidine (TRA306, Amersham, UK) and harvested after $16 \mathrm{~h}$ onto filtermats (Skatron) using a Titertek cell harvester. Filtermats were dried and subjected to scintillation counting in a Packard Scintillation Counter. Thymidine uptake was plotted against the macrophage concentration of each culture.

\section{GLUTARALDEHYDE FIXATION OF MACROPHAGES}

The optimum concentration of glutaraldehyde for fixing macrophages was determined by accessory cell assays (not shown) on macrophages fixed in concentrations of glutaraldehyde between $0.005 \%$ and $0.5 \%$. Normal macrophages fixed at $0.01 \%$ were satisfactory accessory cells and were not deleterious to ConA-activated lymphocytes. To perform fixation, plastic adherent peritoneal cells were suspended in PBS at a concentration of $5 \times 10^{6}$ cells $/ \mathrm{ml}$. Glutaraldehyde was added to the cell suspension to a final concentration of $0.01 \%$ for exactly $30 \mathrm{sec}$. The reaction was stopped by the addition of an equal amount of $0.2 \mathrm{M} \mathrm{L}$-lysine in PBS. The cells were washed three times with PBS and resuspended in tissue culture medium (TCM) containing RPMI-1640 and $5 \%$ NCS (Rakha et al., 1991a).

\section{INDOMETHACIN TREATMENT OF MACROPHAGES}

Indomethacin treatment of macrophages was performed by the method of Holt et al. (1981) and Mattingly et al. (1979). Briefly, indomethacin (Sigma), an 
irreversible inhibitor of prostaglandin synthetase, was dissolved in methanol at $10^{-3} \mathrm{M}$ and diluted to $10^{-6} \mathrm{M}$ with TCM for working dilution. The macrophages, prepared as above, were suspended in the solution and incubated at $37^{\circ} \mathrm{C}$ for $1 \mathrm{~h}$. The suspension was centrifuged and the supernatant discarded. The treated cells were washed twice with TCM.

\section{MACROPHAGE INCUBATION IN VITRO}

Washed macrophages were cultured in TCM (10\% NCS) at $37^{\circ} \mathrm{C}$ in $5 \% \mathrm{CO}_{2}$ and supernatants were collected after $48 \mathrm{~h}$ of incubation. Macrophage supernatants were centrifuged, filtered sterile and stored at - $20{ }^{\circ} \mathrm{C}$. Normal, TMCF-activated and indomethacintreated macrophages were cultured. Supernatants of these cultures at various doses were added to ConAstimulated lymphocyte cultures to study their effect on ConA-driven lymphocyte proliferation.

\section{SEPARATION OF $\mathrm{Ia}^{+}$MACROPHAGES}

For positive selection of $\mathrm{Ia}^{+}$cells, peritoneal macrophages, prepared as above, were incubated with rat monoclonal antibody to Ia antigen (Serotec, Clone No., H116-32-R5, $8 \mu \mathrm{g} / \mathrm{million}$ cells) for $30 \mathrm{~min}$ at $4{ }^{\circ} \mathrm{C}$. The cells were collected by centrifugation at $200 \mathrm{~g}$ for 10 min. Cells were resuspended and washed twice with TCM to remove all unbound antibody. Dynabeads (Dynal $^{\mathrm{TM}}$, Cat. No. M-450) conjugated with sheep antirat IgG, at a concentration of $7.5 \mu$ of beads $/ 10^{6}$ cells were mixed with the cells and incubated for 5-7 min at $4{ }^{\circ} \mathrm{C}$ then placed in the magnetic particle concentrator (Dynal UK). $\mathrm{Ia}^{+}$macrophages adhered to the inner surface of the tube. The supernatant (containing $\mathrm{Ia}^{-}$macrophages) was collected by pipette. The remaining $\left(\mathrm{Ia}^{+}\right)$macrophages detached themselves spontaneously when the tube was removed from the concentrator and were resuspended in TCM. The cell suspension was then replaced in the concentrator and after $1 \mathrm{~min}$ the supernatant was again removed. Such magnetic washings were repeated three times. Cells in TCM were finally collected as $\mathrm{Ia}^{+}$macrophages. The cells in this preparation were found to be $85-90 \% \mathrm{Ia}^{+}$ by indirect immunofluorescence. For negative selection of $\mathrm{Ia}^{-}$macrophages, the procedure adopted was essentially the same except that the Dynabead concentration was $30 \mu \mathrm{l}$ of beads $/ 10^{6}$ cells and the Dynabead incubation time was $15 \mathrm{~min}$ at $4^{\circ} \mathrm{C}$. Non-adherent ( $\left.\mathrm{Ia}^{-}\right)$ cells were collected in three separate successive washings of the tube held in the concentrator.

\section{STAINING OF CELL MEMBRANE DETERMINANTS}

Purified monoclonal antibody against Ia antigens was biotinylated and incubated with cells. The cells were then incubated with streptavidin-FITC and fluorescing cells counted by fluorescence-activated cell sorter (FACS)

To purify the monoclonal antibody, Protein-A Sepharose, $1 \mathrm{~g}$, was swelled in $10 \mathrm{ml}$ of PBS, $0.15 \mathrm{M}, \mathrm{pH} 7.2$ for $1 \mathrm{~h}$ and washed three times with 0.1M PBS pH 8.0. The anti-Ia monoclonal antibody, diluted $1: 1$ with $0.1 \mathrm{M}$ PBS pH 8.0, was mixed with an equal volume of the washed gel, incubated at room temperature for $30 \mathrm{~min}$ then deposited at $250 \mathrm{~g}$ for $2 \mathrm{~min}$. After one wash with PBS the deposit was dissolved in $1 \mathrm{ml}$ of $0.1 \mathrm{M}$ citrate buffer $\mathrm{pH} 3.5$ at room temperature for $10 \mathrm{~min}$. After centrifugation, the supernatant was collected and dialysed against $0.2 \mathrm{M}$ sodium bicarbonate solution.

For biotinylation, monoclonal antibody was dialysed overnight against $0.2 \mathrm{M}$ sodium bicarbonate and protein concentration was adjusted to $1.5 \mathrm{mg} / \mathrm{ml}$ with 0.1 $M$ sodium bicarbonate. Biotin-amidocaproate-Nhydroxysuccinimide ester (Sigma), $25 \mathrm{mg}$, was dissolved in $11 \mathrm{ml}$ of dimethylsulfoxide. This solution was diluted 1:10 before use; $0.1 \mathrm{ml}$ of working solution was added to each $\mathrm{ml}$ protein solution and mixed immediately. The solution was then stirred gently at room temperature for $4 \mathrm{~h}$ and dialysed against PBS overnight.

\section{Ia STAINING OF MACROPHAGES}

Macrophages prepared as above were washed three times with PBS. $5 \times 10^{5}$ viable cells were suspended in $1 \mathrm{ml}$ of $10 \%$ normal rat serum, incubated at $4{ }^{\circ} \mathrm{C}$ for $20 \mathrm{~min}$, washed once with PBS and incubated with $2 \mu \mathrm{g}$ biotinylated monoclonal antibody in $100 \mu \mathrm{l}$ volume at $4^{\circ} \mathrm{C}$ for $20 \mathrm{~min}$. After three washes, $1 \mathrm{ml}$ of cell suspension in PBS was incubated with $100 \mu \mathrm{l}$ of streptavidin-FITC at $1 \mathrm{mg} / \mathrm{ml}$ concentration. The cells were finally washed four times with PBS, suspended in $0.5 \mathrm{ml}$ of PBS and analysed on a FACS- 420 (FACS II Becton and Dickinson) gated to exclude non-viable cells. A total of 10,000 cells was counted and the number of fluorescent cells recorded as a percentage.

\section{RESULTS}

\section{ACCESSORY FUNCTION}

OF GLUTARALDEHYDE-FIXED MACROPHAGES

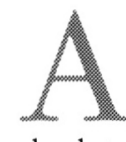
ccessory function of glutaraldehyde-fixed macrophages was studied by progressively adding them to ConA-activated, macrophagedepleted lymph-node cells which were then assayed for proliferation. Glutaraldehyde-fixed, normal macrophages had a positive accessory function; fixed TMSNactivated macrophages had a negative accessory function which became more pronounced as the macrophage concentration increased (Fig. 1). These 


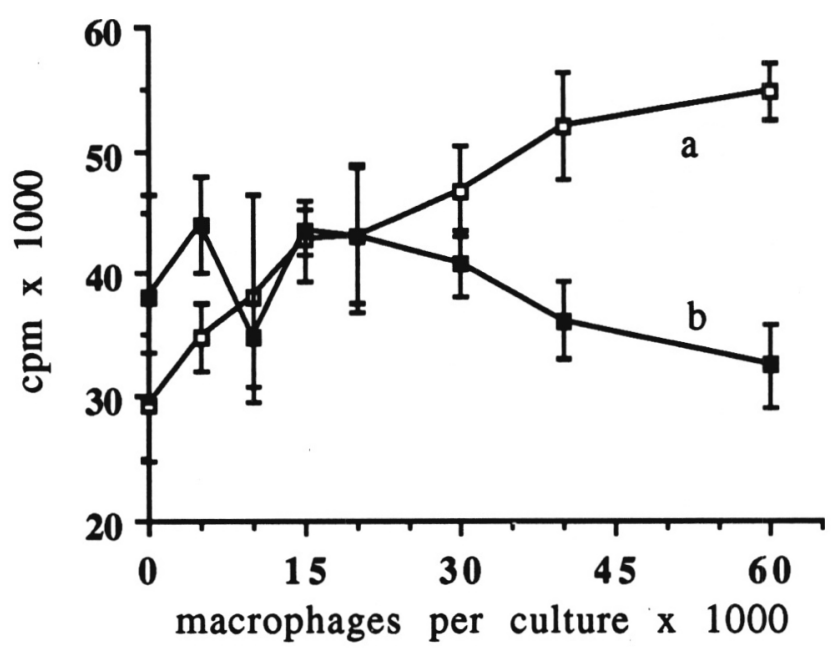

Fig. 1 - 3H-thymidine uptake by normal, ConA-activated, macrophage-depleted, BALB/c lymph node cells supplemented by glutaraldehyde-fixed, syngeneic peritoneal macrophages; $a=$ macrophages from normal mice; $b=$ macrophages from mice 3 days after double intraperitoneal injection of T. multiceps culture supernatant

effects are similar to those exerted by living normal or TMSN-activated macrophages (Rakha et al., 1991a). This indicates that both normal and T. multiceps-modified macrophages exert their particular effects by means which are at least partly independent of metabolism.

\section{MODIFIED ACCESSORY FUNCTION IS ASSOCIATED WITH REDUCTION IN THE Ia-POSITIVE MACROPHAGE POPULATION}

Since the Ia determinant is important in the mediation of accessory cell activity, we investigated the effect of the macrophage modifying regime on the expression of Ia. TMSN was injected on days 0 and 7 , and cells collected on day 10 . At this time the $\mathrm{Ia}^{+}$population was less than $25 \%$ of the control value (Fig. 2).

Modification of accessory cells has previously been associated with FPLC fraction 24 of T. multiceps secretions. It was therefore of interest to find out whether this same fraction were also responsible for reducing the $\mathrm{Ia}^{+}$population of the macrophages.

Figure $3 a$ shows that incubation of peritoneal cells with either TMCF or TMCF-F24 at $10 \%$ by volume reduced the proportion of $\mathrm{Ia}^{+}$cells in the population [MannWhitney U test for TMCF-F24 incubation: at each time interval, $n=5, \mathrm{U}=0, p$ (two-tailed) $<0.05$ ]. Figure $3 b$ shows the result of injecting TMCF-F24 into the peritoneum twice at one week's interval and testing for $\mathrm{Ia}^{+}$ expression 3 days later. The proportion of $\mathrm{Ia}^{+}$cells was again reduced by this treatment $(p<0.05)$.

The role of Ia in modified accessory function was also investigated by artificially manipulating the numbers of $\mathrm{Ia}^{+}$cells in the population. The accessory activity of

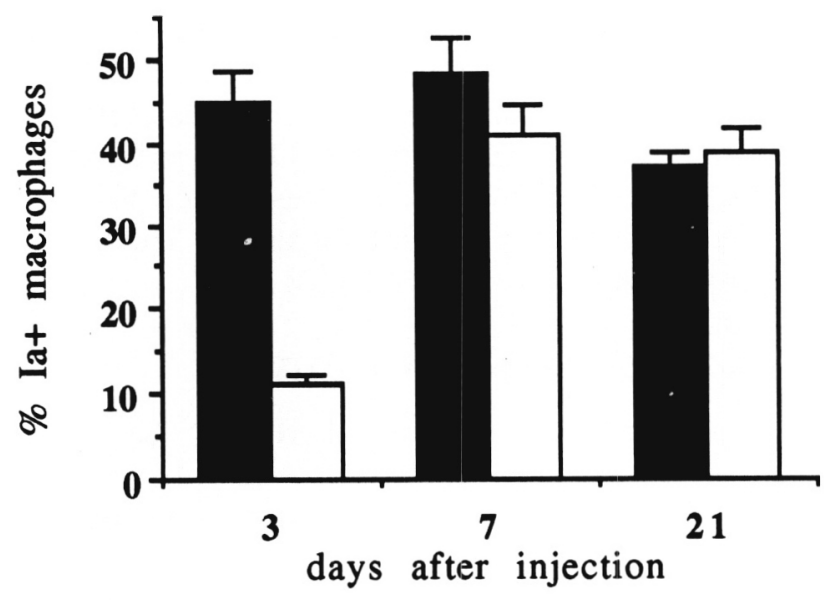

Fig. 2. - FACS analysis of peritoneal macrophages binding the biotinylated anti-Ia monoclonal antibody H116-32-R5. Mice were injected intraperitoneally twice at 7 days interval with: culture medium; $\square$ T. multiceps culture supernatant. Macrophages were collected 3 days later.
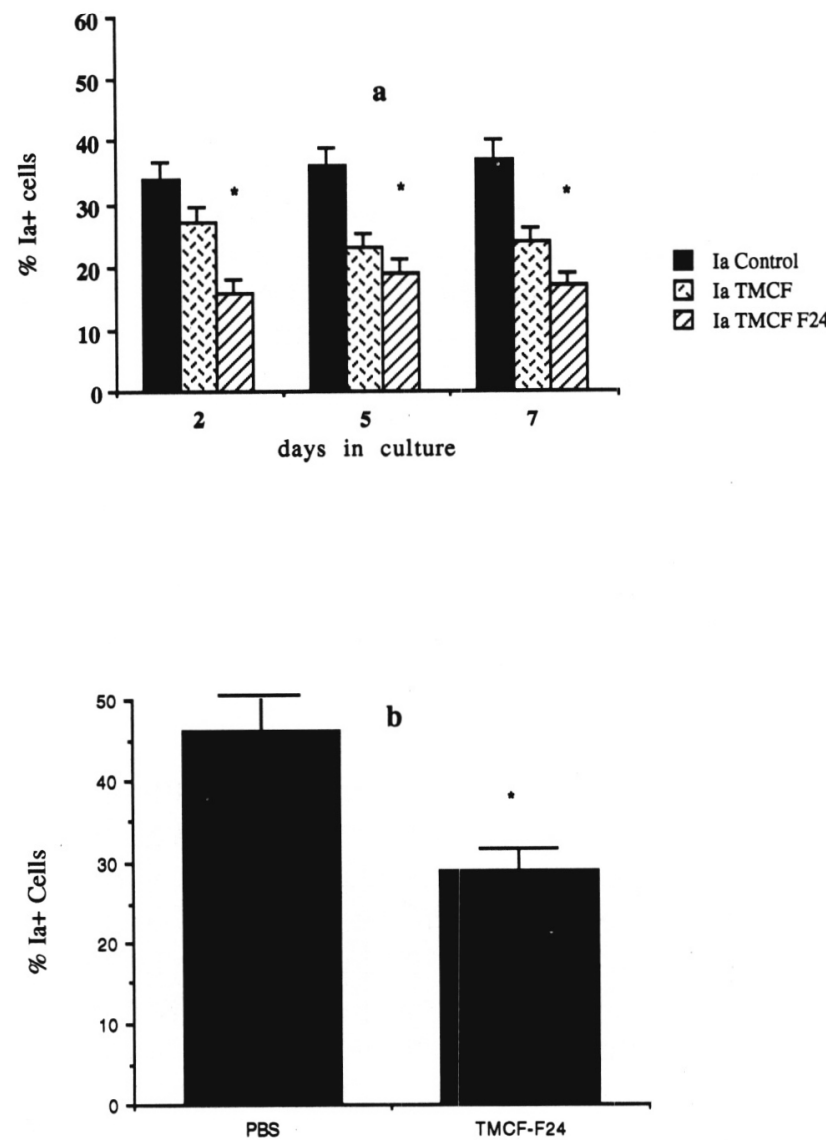

Fig. 3. - Percentage of $\mathrm{Ia}^{+}$macrophages a) in peritoneal cells following incubation in vitro with $T$. multiceps cyst fluid or with TMCF-F24 (10\%); b) following two intraperitoneal injections at one week's interval of TMCF-F24 (* significant reduction with F24, $p<0.05)$. 
peritoneal cells, after activation in vivo by TMSN and subsequent Ia-specific Dynabead separation, is shown in Figure 4, from which it can be seen that the typical modified activity is associated with the Ia- population, the effect of the cells being depressive at concentrations over 15,000 per culture.

\section{METABOLIC ACTIVITY OF MODIFIED MACROPHAGES}

Figure 1 indicates that both normal and T. multicepsmodified macrophages exert characteristic accessory effects in the fixed state. This still allows the possibility that accessory activity of normal and modified macrophages can also be mediated by secreted products of the living cells. We investigated this by collecting cell culture supernatants from normal and parasite-modified macrophages, and adding the fluids to mitogen-stimulated lymphocytes. It was found in a pilot experiment [not shown] that supernatant cultures of both normal and parasite modified macrophages were suppressive for phytohaemagglutinin-activated lymphocyte transformation. Supernatants from modified cells were significantly more active in this respect. Given the suppressive nature of macrophage supernatant, it was of obvious interest to identify the active principle in the secretion. To examine the possibility that prostaglandins were mediators of the effect, macrophages modified by TMCF injection were treated with indomethacin, an irreversible inhibitor of prostaglandin synthesis, washed and cultured for $48 \mathrm{~h}$. The supernatant fluid from these, or from untreated, modified macrophages, was then added in varying concentration to ConA-stimulated lymphocyte cultures. The result (Fig. 5a) showed that supernatant of untreated modified macrophages mediated an effect similar to the modified cells themselves. This effect was largely abolished if the modified macrophages had been treated with indomethacin (Fig. 5b).

The assay of accessory cell activity in these experiments depends on measuring ${ }^{3} \mathrm{H}$-thymidine uptake by lymphocytes. It was considered possible that interference with ${ }^{3} \mathrm{H}$-thymidine uptake could have occurred by reason of cold thymidine secretion by macrophages. Such cold thymidine would compete with ${ }^{3} \mathrm{H}$-thymidine and therefore lower the radioactive count of harvested lymphocyte cultures. To examine this possibility, progressively increasing doses of macrophage culture supernatant were applied to phytohaemagglutinin-activated lymphocyte cultures which were subsequently pulsed with 3 different doses of ${ }^{3} \mathrm{H}$-thymidine. The result (Fig. 6) shows that the suppressive effect of the supernatant on ${ }^{3} \mathrm{H}$-thymidine uptake was substantially the same at all doses of ${ }^{3} \mathrm{H}$-thymidine. This indicates that competition from cold thymidine is not an important effect in these experiments.

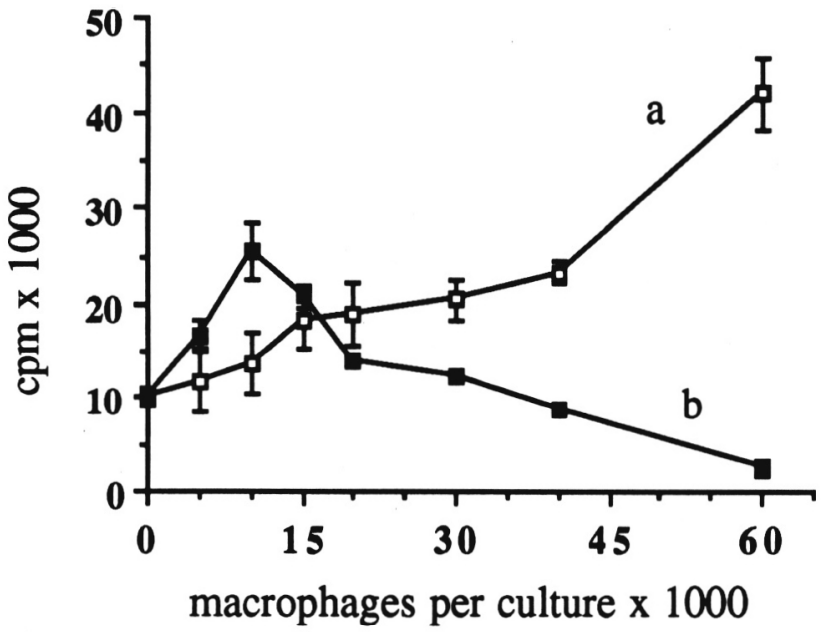

Fig. 4. - Thymidine uptake by ConA-stimulated, macrophagedepleted, normal lymphocyte cultures supplemented with (a) $\mathrm{Ia}^{+}$or (b) Ia- TMSN-activated macrophages.

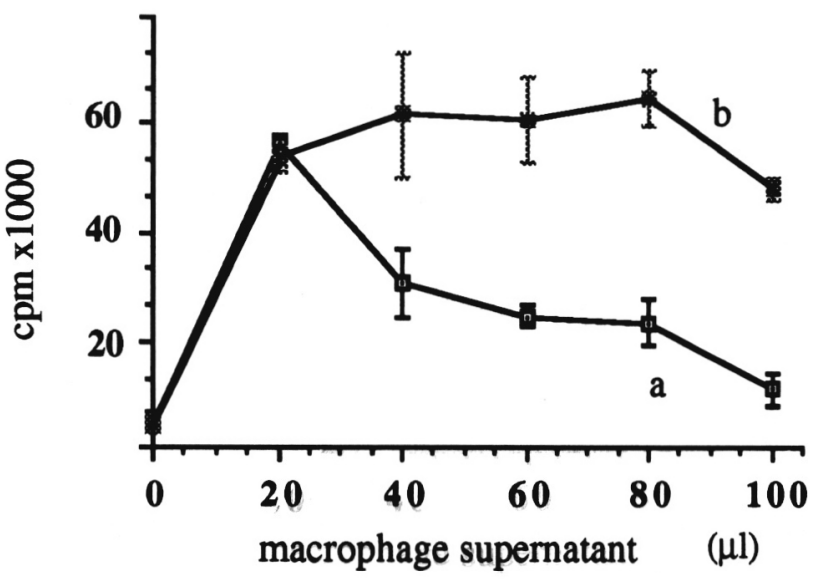

Fig. 5. - Thymidine uptake by ConA-stimulated normal lymphocytes supplemented with supernatant of (a) T. multiceps-modified, untreated macrophages, (b) T. multiceps-modified, indomethacintreated macrophages.

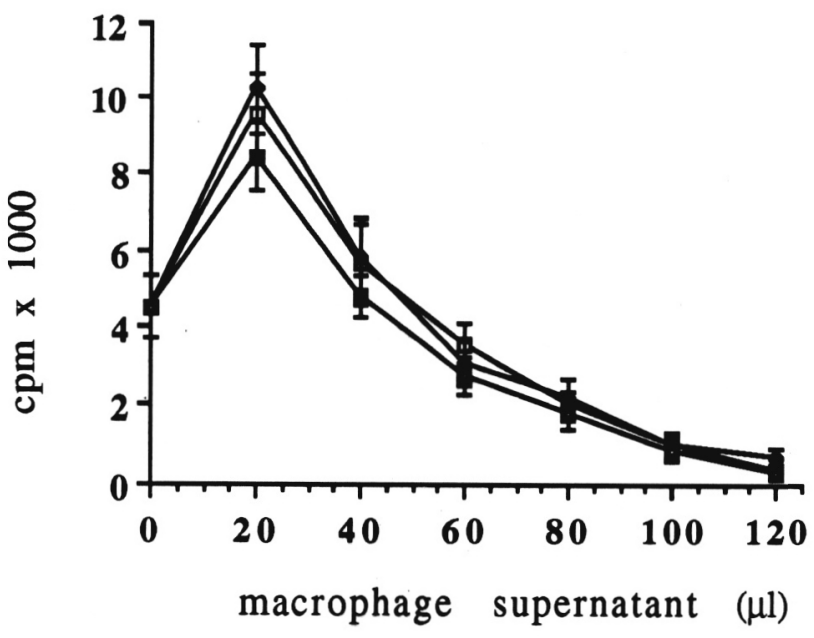

Fig. 6. - Thymidine uptake by phytohaemagglutinin-stimulated normal lymphocyte cultures supplemented with macrophage culture supernatant and labelled with: o $4.0 \mu \mathrm{Ci}, \bullet 1.0 \mu \mathrm{Ci}, 0.25 \mu \mathrm{Ci}$ tritiated thymidine. 


\section{DISCUSSION}

T These experiments confirm that altered accessory-cell activity can be induced by T. multiceps secretions (Rakha et al., 1991a). The investigation concerns the plastic-adherent compartment of the peritoneal cell population, and shows that these peritoneal macrophages were impaired as accessory cells after exposure to T. multiceps cyst fluid or culture supernatant. This does not, by itself, predict the changes which $T$. multiceps may possibly induce in the leucocytic system as a whole, but shows that the parasite has potential influence over at least one important link in the induction of acquired immunity, macrophage-T-cell interaction. This would be expected to interfere with induction of antigen-specific lymphocytes, and such an effect has previously been demonstrated in vivo (Rakha et al., 1991b), the mediating factor being FPLC fraction 24 of T. multiceps, the fraction employed in the present study.

We report here for the first time that $T$. multiceps-activated macrophages can mediate modified accessory activity after glutaraldehyde fixation (Fig. 1). Metabolic activity by these macrophages being precluded, the action of the cells is presumably determined by changes in the cell membrane. Class II MHC molecules are among the most important involved in antigen presentation by accessory cells (Conzen and Janeway, 1988), and we therefore investigated by flow cytometry the distribution of macrophages binding the Ia-specific monoclonal antibody, H116-32-R5, in normal and parasite-activated populations. Injection of $T$. multiceps culture supernatant into the peritoneum produced a macrophage population poor in $\mathrm{Ia}^{+}$cells (Fig. 2). Incubation of macrophage cultures with coenurus fluid, or FPLC fraction 24 of coenurus fluid, markedly reduced the proportion of $\mathrm{Ia}^{+}$cells (Fig. $3 a$ ). Intraperitoneal injection of fraction 24 had a similar effect on the peritoneal cell population (Fig. $3 b$ ). In peritoneal macrophages activated by injection of parasite supernatant, the modified accessory activity was found in the $\mathrm{Ia}^{-}$ compartment of the macrophages. Conversely, the $\mathrm{Ia}^{+}$ compartment, purified by positive selection, showed normal, positive accessory function (Fig. 4). These results indicate that the macrophage membrane plays a part in mediating modified accessory function, and that modified cells lack Ia. Presumably the increased proportion of $\mathrm{Ia}^{-}$cells in modified populations could arise by the destruction of Ia+ cells, the conversion of $\mathrm{Ia}^{+}$cells to $\mathrm{Ia}^{-}$, or (at least in vivo) the recruitment or multiplication of Iar cells. The characteristic effect of the modified, Ia ${ }^{-}$macrophage may result from an inability to present Class-II-restricted signals (see Cox et al., 1986), but further work will be required to prove this.
The involvement of the macrophage membrane in modified accessory activity does not preclude the possibility that the modified cell also exerts an effect via a secreted messenger. Supernatant fluid of cultured peritoneal macrophages depressed lymphocyte mitosis in proportion to concentration (not shown), the effect being enhanced when modified rather than normal macrophages were used. Also in modified macrophages, the secretion of the depressive factor was prevented by incubation with indomethacin (Fig. 5), indicating that prostaglandin is probably at least one mediator of modified macrophage-T-cell interaction in parasite-activated systems. Thymidine was not detected in the secretions of macrophages (Fig. 6).

The effects of indomethacin in restoring normal accessory activity to modified macrophages are difficult to explain in molecular terms, because of the wide ranging effects this agent has on cell physiology. However, as indomethacin mainly functions by irreversibly blocking PG synthetase, it is likely to be inhibiting secretion of $\mathrm{PGE}_{2}$, and this has a number of immunological implications relevant to metacestode immunity. For example, several accessory cell activities are increased by the action of $\mathrm{PGE}_{2}$ inhibitors, including antigen presentation, TNF $\alpha$ and IL-1 synthesis, Ia expression (Ertel et al., 1993) and particularly the preservation of antigen presentation by macrophages (Redmond et al., 1995). $\mathrm{PGE}_{2}$ also induces IL-10 release by $\mathrm{T}$ helper cells (Ayala et al., 1994); the latter cytokine is very potent at abrogating macrophage activities. Thus, the effects seen with indomethacin in this study are consistent with its known ability to reverse immunosuppression mediated by macrophages.

Interference with macrophage-T-cell interaction is a means by which metacestode parasites could impair antigen recognition and the organisation of immune defence. The importance of this to the host-metacestode relationship is further suggested by the fact that two other species, Echinococcus multilocularis (Rakha et al., 1991c) and Mesocestoides corti (Kadian et al., 1994) show similar faculties. In both cases modified accessory cells can be generated by infection or by the injection of parasite secretion. Strong serological cross reaction was shown between fraction 24 of coenurus and hydatid fluid (Rakha, unpublished). M. corti fraction 24 has also been used as an antigen to produce a murine monoclonal antibody with binding affinity for the homologous fraction and the ability to antagonise its macrophage modifying effect in vivo and in vitro (Kadian, 1995). In M. corti at least, the modifying factor and the antigen are, therefore, apparently identical. Accordingly, the immunoregulatory function of metacestode modifying factors could be compromised by host antibody response, while at the same time modifying factors could impair antibody production. 
This negative-feedback arrangement would constitute a primary homeostatic mechanism for the regulation of immune response to all metacestode antigens.

Assuming that accessory-cell modification is significant to the host-metacestode relationship, two major questions are the molecular structure of the modifier and its effect on the duration of parasitism. So far, the antigenicity of $T$. multiceps modifying factor has been found to be destroyed by protease but not amylase, neuraminidase or trypsin (Rakha, unpublished), while in $M$. corti, the modifying activity has been found in association with two western blot fractions with approximate molecular weights of $56 \mathrm{kDa}$ and $26 \mathrm{kDa}$ (Kadian, unpublished). It is hoped that the existence of monoclonal antibody will permit the isolation by affinity chromatography of modifying factor from at least one metacestode species. The effect of modifying factors on host-parasite relationship can be studied directly in infection models with M. corti and Echinococcus sp., and these experiments are in progress. It is hoped that sufficient knowledge of the immunoregulatory mechanisms governing metacestode parasitism may provide a rationale for immunotherapeutic intervention.

\section{ACKNOWLEDGEMENTS}

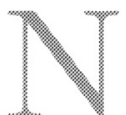

.K. Rakha was supported by a scholarship from the Association of Commonwealth Universities. We thank Peter Kern for advice and criticism.

\section{REFERENCES}

Ayala A., Lehman D.L., Herdon C.D. \& Chaudry I.H. Mechanism of enhanced susceptibility to sepsis following hemorrhage - Interleukin-10 suppression of T-cell response is mediated by eicosanoid-induced interleukin-4 release. Archives of Surgery, 1994, 129, 1172-1178.

Conzen S.D. \& Janeway C.A. Defective antigen presentation in chronically protein-deprived mice. Immunology, 1988, 63, 683-689.

Cox D.A., Dixon J.B. \& Marshall-Clarke S. Transformation induced by Echinococcus granulosus protoscoleces in unprimed murine spleen cells: identity and MHC restriction of participating cell types. Immunology, 1986, 57, 461-466.

Dixon J.B., JENkINS P. \& ALLAN D. Immune recognition of Echinococcus granulosus. 1. Parasite-activated, primary transformation by normal murine lymph node cells. Parasite Immunology, 1982, 4, 33-45.

Ertel W., Morrison M.H., Ayala A., Perrin M.M. \& ChAudry I.H. Blockade of prostaglandin production increases cachectin synthesis and prevents depression of macrophage functions after hemorrhagic shock. Annals of Surgery, 1991, 213, 265-270.
Holt P.G., Warner L.A. \& MaYrhofer G. Macrophages as effectors of $\mathrm{T}$ suppression: T-lymphocyte dependent macrophage mediated suppression of mitogen induced blastogenesis in the rat. Cellular Immunology, 1981, 63, 57-70.

Kadian S.K., Dixon J.B., Green J.R., Carter S.D. \& Jenkins P. Modification of macrophage- $\mathrm{T}$ cell interaction during infection of mice with Mesocestoides corti (Cestoda). Parasitology, 1994, 109, 591-597.

Kadian S.K., Dixon J.B., Carter S.D. \& Jenkins P. Macrophage modifying factor secreted by the tetrathyridia of Mesocestoides corti (Cestoda): monoclonal antibody to the modifying factor antagonises its immunological activity. Parasite Immunology, 1996, 18, 65-70.

Mattingly J.A., Eardley D.D., Kemp J.D. \& Gershon R.K. Induction of suppressor cells in rat spleen: influence of microbial stimulation. Journal of Immunology, 1979, 122, 787-794.

Rakha N.K., Dixon J.B., Skerritt G.C., Carter S.D., Jenkins P. \& MarShall-Clarke S. Lymphoreticular responses to metacestodes: Taenia multiceps (Cestoda) can modify interaction between accessory cells and responder cells during lymphocyte activation. Parasitology, 1991a, 102, 133-140.

Rakha N.K., Dixon J.B., Jenkins P., Carter S.D., Skerrito G.C. \& MARShall-Clarke S. Modification of cellular immunity by Taenia multiceps (Cestoda): accessory macrophages and CD 4+ lymphocytes are affected by two different coenurus factors. Parasitology, 1991b, 103, 139-147.

Rakha N.K., Dixon J.B., Carter S.D., Craig P.S., Jenkins P. \& FOLKARD S. Echinococcus multilocularis antigens modify accessory cell function of macrophages. Immunology 1991c, 74, 652-656.

Rakha N.K., Dixon J.B., Skerritt G.C., Carter S.D. \& Jenkins P. Modification of accessory activity of sheep monocytes in vitro by a coenurus antigen from Taenia multiceps. Veterinary Immunology and Immunopathology, 1992, 30, 293304.

Redmond H.P., Gallagher H.J., Shou, J. \& Daly J.M. Antigen presentation in protein-energy malnutrition. Cellular Immunology, 1995, 163, 80-87.

Skerritt G.C. \& Stallbaumer M.F. Diagnosis and treatment of coenurosis (gid) in sheep. Veterinary Record, 1984, 115, 399-403. 